\title{
El ego conquiro como inicio de la modernidad
}

\author{
Rudy Montano
}

Recibido el 4 de abril de 2017, aceptado para su publicación el 14 de agosto de 2017

\begin{abstract}
Resumen
En este artículo se pretende demostrar los elementos que caracterizan el ego conquiro, es decir un sujeto "pre-moderno". El análisis se hace a partir del hecho de la conquista de América por parte de los europeos. El objetivo de la conquista es adquirir territorios, y al mismo tiempo, colonizar al indígena de América no sólo físicamente, sino ideológicamente. Este tema corresponde a uno de los aspectos que conforman la filosofía de la liberación de Enrique Dussel.
\end{abstract}

El objetivo de este escrito es demostrar que la constitución del ego conquiro es el punto de partida, el inicio del proceso de constitución del victimario en sujeto. Es de vital importancia, para poder abordar la liberación de la víctima, hablar sobre cómo el victimario se constituye en sujeto desde la dialéctica de la dominación. La racionalidad del ego conquiro genera prácticas que desembocan en la generación de víctimas. El artículo se desarrollará en cuatro partes. La primera explica en qué consiste el proceso de constitución del ego conquiro. La segunda hace referencia, a consecuencia de ese proceso, a la relación dialéctica descubrimiento-encubrimiento del otro que obliga a preguntarnos por la dialéctica racionalidad-irracionalidad. La tercera plantea el problema de la colonización y el eurocentrismo como elementos propios del ego conquiro. Finalmente, la Conclusión recogerá las afirmaciones trabajadas y se centrará en la crítica a la afirmación de Enrique Dussel: "el ego conquiro es el inicio de la modernidad"?.

\section{Palabras clave}

Ego conquiro, dialéctica de dominación, víctima, América Latina, nuevo mundo, Enrique Dussel.

1. Rudy Eduardo Montano Renderos, Licenciado en Teología por la Universidad Centroamericana José Simeón Cañas de San Salvador, Docente de la Escuela de Teología, Universidad Don Bosco. 2. Esto se afirma en E. DUSSEL, 1492. El encubrimiento del otro. Hacia el origen del mito de la modernidad, Plural Edit., La Paz, 1994, p. 21 


\begin{abstract}
This article aims to demonstrate the elements that characterize the 'ego conquiro', that is, a 'pre-modern' subject. The analysis is done from the fact of the conquest of America by Europeans. The objective of the conquest is to acquire territories, and at the same time, colonize the indigenous of America not only physically, but ideologically. This theme corresponds to one of the aspects thatmake up the philosophy of the liberation of Enrique Dussel.
\end{abstract}

The objective of this paper is to demonstrate that the conquiro ego constitution is the starting point, the beginning of the process of constituting the victimizer in the subject. It is of vital importance, in order to address the liberation of the victim, to talk about how the perpetrator becomes a subject from the dialectic of domination. The rationality of the ego conquiro generates practices that lead to the generation of victims. The article will be developed in four parts. The firstexplains what the conquiro ego constitution process consists of. The second one makes reference, as a consequence of this process, to the dialectical relation discoveryconcealment of the other that forces us to ask ourselves about the dialectic rationality-irrationality. The third raises the problem of colonization and Eurocentrism as elements of ego conquiro. Finally, the Conclusion will collect the affirmations worked on and focus on the criticism of Enrique Dussel's statement: "the ego conquiro is the beginning of modernity".

\title{
Keywords
}

Ego conquiro, dialectic of domination, victim, Latin America, new world, Enrique Dussel.

\section{Aclaración de términos}

Antes de entrar en el desarrollo del tema, se hace necesario hacer algunas aclaraciones terminológicas que facilitarán la lectura.

El primer término es ego conquiro. Éste se puede definir como un ego (yo) previo al ego cogito (yo pienso) que se gesta en el contexto de la conquista y colonización de América. Este ego tiene la praxis de conquistar y someter y el objetivo de "civilizar" a aquellos que no están civilizados. "Civilizar" equivale en este contexto a "occidentalizar" al que no está "occidentalizado".

El segundo término es dialéctica de la dominación3. Es el término que Dussel utiliza para hablar la forma en que la filosofía de la Modernidad ha contribuido a que se vaya gestando una dialéctica que olvida el mundo, la realidad, lo sensible 
y se centra en lo abstracto, a tal grado que deriva en una ontología, una forma de concebir al ser como absoluto, como uno, como todo y cuyo punto de partida es el ego cogito. En consecuencia, esta ontología genera un modo de ver la historia desde el dominador que desde el pensamiento de Dussel es considerado el victimario; sus valores como victimario son el éxito, el triunfo y las grandes conquistas que ha realizado y seguirá realizando en la historia.

El tercer término es el de víctima4. Nos estamos refiriendo a aquél o aquélla que está en situación de dominado, sometido, que ha sido reducido a nada. Para el victimario la víctima es el no-ser, el que no debe ser tomado en cuenta, el que no significa nada para la historia, un no-sujeto. Es la cara opuesta de la dialéctica de la dominación.

\section{El proceso de constitución del ego conquiro}

El ego conquiro nació, se manifestó y se consolidó durante la época de la América colonial. Desde nuestro punto de vista, se puede afirmar que el ego conquiro se construyó en torno a cuatro aspectos: en primer lugar, el encuentro con el nuevo mundo; en segundo lugar, la construcción de un "discurso" en el que el indígena queda "integrado" a la nueva cultura occidental; en tercer lugar, el sometimiento y en cuarto lugar, la civilización, es decir, introducir al indígena a la visión de ciudadanía desde la visión de la modernidad.

El primer aspecto, el encuentro y la conquista del Nuevo Mundo, es un hecho que consiste en "descubrir" el Nuevo Mundo, tanto el territorio como los que lo habitan. Es un descubrimiento de un mundo desconocido y también un encuentro cara-a-cara con el habitante "desconocido". Este encuentro implica también una exploración-búsqueda, es decir, el deseo de conocer o "reconocer" lo ya conocido. En este sentido, podemos establecer una especie de tensión entre "descubrir lo desconocido" y "descubrir lo ya conocido". Esto se concreta en la experiencia que sostiene Cristóbal Colón quien, al descubrir el nuevo mundo, lo ve ya conocido. Lo descubre como la misma Asia o el "mundo asiático". Dussel le llama "la invención” del ser asiático en América:

"Esto es lo que llamamos la "invención" del "ser-asiático" de América. Es decir, el "ser-asiático" de este cozntinente sólo existió en el "imaginario" de aquellos europeos renacentistas. Colón abrió, política y oficialmente, en Europa la puerta al Asia por el Occidente". ${ }^{5}$

Lo que hicieron los "descubridores" fue una "ontología de lo asiático", es decir, identificaron el territorio descubierto como otra forma de expresión de lo asiático. Aquello que era desconocido forma parte de un universo llamado

4. Este término aparece desarrollado en DUSSEL, E., Ética de la liberación en la edad de la globalización y la exclusión. Trotta, Madrid, 1998, pp. 309ss.

5. DUSSEL, E. 1492. El encubrimiento del Otro, op. cit, p. 29. 
“lo asiático". Con la expresión “lo asiático”, nos referimos a la palabra que el ego conquiro utiliza para describir e interpretar lo que ha descubierto. Lo que es "distinto" se hace "universal" desde el imaginario del europeo renacentista. Aunque la experiencia de mirar, descubrir y explorar produce admiración en los conquistadores, ellos llegarán a la conclusión que aquello que se ha descubierto sólo entra en lo que se llama "el ser asiático". Por eso se le llama una "ontología de lo asiático".

Este deseo se transforma en un "hacer", es decir el ego conquiro explora con mayor detalle lo ya descubierto. Toma una actitud de observación pre-investigativa, pre-científica. Es decir, dicha exploración no tiene una finalidad científica, en principio; sólo observa para continuar después con el proceso de conquista y colonización.

El segundo aspecto es el encuentro cara-a-cara seguido del diálogo. Al realizar el descubrimiento y exploración del entorno y de quien habita en él, el conquistador elabora un "discurso" que sólo tendrá sentido en un encuentro cara-a-cara con el futuro conquistado; después del encuentro cara-a-cara viene el "diálogo amistoso" que más bien es una "declaración de sometimiento" que el futuro conquistado deberá aceptar; en este sentido el ego conquiro tiene la esperanza de tener una respuesta favorable del conquistado, tendrá éxito. En consecuencia, el encuentro cara-a-cara se convertirá en un movimiento unilateral. Unilateral en el sentido que es el ego conquiro quien impondrá las condiciones del diálogo cuyo único resultado será que el conquistado se deje someter.

El tercer aspecto es el sometimiento. El ego conquiro someterá al indígena por la violencia; su experiencia será de éxito, de triunfo; el descubridor y explorador se convierte en este momento en ego conquiro. El conquistado, el indígena, tienXe una "conversión" también: pasa de ser un "conquistado en potencia" a ser un "conquistado en acto"; pasa de vivir de manera autónoma y libre (con su propia cultura, tradición, religión, etc.), a quedar sometido a la libertad del ego conquiro (quien le impondrá una cultura, una tradición, una religión, etc.). Someter o colonizar es un proceso que comienza con el éxito de haber logrado someter al conquistado de forma violenta.

El cuarto aspecto se refiere al segundo objetivo del ego conquiro: introducir al conquistado a la "civilización"; el encuentro cara-a-cara se transforma en desencuentro o, como dirá Axel Honeth, en menosprecio (hacia el conquistado), es decir, "un comportamiento que va a perjudicar la libertad de acción del conquistado y que lesiona el entendimiento positivo de sí mismo"6. En esta cita de Honeth se vislumbran las consecuencias del sometimiento: se perjudica la libertad y la autoestima del sometido. Este es el momento decisivo para el inicio del proceso civilizatorio: utilizando como recurso la violencia, el ego conquiro 
impondrá su hegemonía sobre el "desconocido" indígena; es decir, tomará hacia él una actitud de menosprecio, de minusvaloración, de reducir al indígena a nada. En consecuencia, el conquistador impone la "civilización" al conquistado para hacerlo "ciudadano". Sin embargo, este cambio implica que el conquistado no será un ciudadano del mismo nivel que el ciudadano europeo. Su inserción a la "ciudadanía" será en un nivel menor, como sometido, esclavizado; su praxis será como trabajador, y no una praxis de determinación política de un ciudadano.

El dominado se somete a la subjetividad del dominador. El dominador ve al dominado como un no-sujeto, sin "anima"; es salvaje y, por tanto, tiene que ser "civilizado" por el que "ya está civilizado". En definitiva, se constituye la "subjetividad" del conquistador dominando y el conquistado aparece como “objeto" de conquista. Bartolomé de las Casas refiere a esta situación en uno de sus escritos, en los que hace referencia a la violencia con la que fueron arrasados los indígenas y la esclavitud a la que fueron sometidos ${ }^{7}$.

\section{El descubrimiento como encubrimiento del otro: racionalidad frente a irracionalidad}

El descubrimiento no se da como un descubrimiento del otro como otro, sino como descubrimiento de "Lo mismo" de Europa ${ }^{8}$, en el sentido que la identidad del otro se construye e impone desde la visión del ego conquiro y no desde el conquistado mismo. Se destruye su "mundo de la vida", para dar lugar al "mundo de la vida" del ego conquiro. Esto lo realiza a través de lo que se llama la "praxis de dominación", es decir, lo que tendrá que "hacer" el conquistador para colonizar al conquistado. El conquistador, en su mundo de la vida sólo ve dos aspectos: animales, objetos y a sí mismo; no vio sujetos más que a sus mismos amigos europeos. Cuando hablamos del mundo de la vida nos referimos a "el mundo tal como se nos presenta en la percepción, anteriormente a cualquier consideración científica. Nos referimos al mundo en tres ámbitos: el históricocultural (hay una historia previa), biográfico-individual (además de la historia, es el individuo el que la vive) y epistemológico (es decir, los elementos que el científico necesita para realizar ciencia, para explicar algo $)^{9}$.

En consecuencia, se expresa una ideología de someter y anular al otro: "estoy seguro que puedo someter al otro". En definitiva, el ego conquiro tiene la confianza, la capacidad y el dynamis necesario para reducir al otro a objeto. Construye su propia historia a costa de la destrucción de la historia del dominado.

7. Cfr. DE LAS CASAS, Bartolome, La destrucción de las indias. Clásicos Ucieza, Barcelona, 1997, pp. 13-16.

8. Dussel aborda este problema al inicio del libro sobre el encubrimiento del Otro cuando hace referencia a la "invención" del ser asiático de América. Cf. Dussel, 1492. El encubrimiento del otro, op cit, pp. 23-31.

9.Cfr. Esta definición del mundo de la vida proviene de la filosofía de Edmund Husserl. Cfr. RUIZ, J. De Heidegger a Habermas. Hermenéutica y fundamentación última en la filosofía contemporánea. Herder, Barcelona, 1997, p. 47ss. 
Tiene la "racionalidad suficiente y necesaria" para someter al conquistado y hacerle entrar en razón. En consecuencia, la subjetividad del conquistador o dominador se constituye a expensas del ser del otro, del sometido. Su subjetividad, entonces, se impone frente a la del otro (no-otro), el fracasado, el conquistado, el irracional. Se genera la dialéctica: éxito (racional) en confrontación con el fracaso (irracional). Desde la dialéctica de la dominación, se demuestra que la historia ha estado a favor del conquistador, ocultando la historia del conquistado; no es la historia del encuentro amistoso, sino la del éxito del conquistador frente al fracaso y sometimiento del conquistado.

Esta praxis de dominio va gestando también la tensión entre la "racionalidad" del ego conquiro frente a la "irracionalidad" del conquistado. Esta tensión, racionalidad frente a irracionalidad, es la que plantea el motivo de lo "natural" del sometimiento del conquistador hacia el conquistado. La explicación de esta tensión racionalidad e irracionalidad, la elabora McPherson en una de sus obras que presentamos a continuación. ${ }^{10}$

En primer lugar el conquistado, como no tiene racionalidad, no puede insertarse en una sociedad civil, no puede ser ciudadano. Entonces tiene que renunciar a su cultura, tradiciones y religión "atrasadas" para llegar a ser un ciudadano "productivo" para la sociedad. Se le niega su capacidad creadora de cultura y de ciudadanía y sólo será civilizado si forma parte de la sociedad como "herramienta de trabajo".

El conquistado o sometido es irracional porque no tiene la capacidad de vivir de acuerdo a la ley natural o de la razón. La irracionalidad se expresa precisamente en que los sometidos no son sujetos de la cultura occidental porque no tienen las costumbres, tradiciones y religión propias de occidente. Sus costumbres religiosas, sociales y culturales necesitan ser encauzadas por el buen camino de la razón y la civilización, debido a que las que ellos tienen, son irracionales, primitivas, atrasadas. Además, el ego conquiro tiene la capacidad para apropiarse del territorio del conquistado porque no tiene las herramientas necesarias para desarrollar su "hábitat" natural. McPherson, comentando a Locke, lo expresa de la siguiente forma:

“La argumentación de Locke sobre la ocupación de América, no se basó en el tema de la abundancia de la tierra, sino en la regla de un derecho natural ilimitado a la propiedad" 11 .

En segundo lugar, la conquista de la tierra también se relacionó con el concepto de "propiedad". El conquistador, además de apropiarse de las personas, se apropiará del territorio que estas personas poseen. Éstas tenían su tierra no en base a la ley natural, sino en base a un estado de naturaleza (un pueblo indígena que ha sido 
descubierto se encuentra para el europeo en un estado de naturaleza (es decir, no tiene la ciudadanía), pero sin razón. Por tanto, El ego conquiro, el racional, impondrá una "forma de ser" al "irracional", no sólo basada en lo ideológico, sino también en lo que posee, en sus propiedades. El "irracional”, el conquistado, pasa de estar en "un estado de naturaleza", en el que estaba inserto sin uso de razón (con esto no se sigue la idea de Locke de que la razón también está en el estado de naturaleza), a una "ley natural", que debe asimilar. Sin embargo, esta inmersión del conquistado en la ley natural sólo tendrá sentido si la impone el conquistador. Para el conquistador, el irracional no dejará de ser irracional, aunque se le "inculquen" tradiciones, religión y cultura propias de la sociedad occidental. Siempre será un esclavo, un sometido, que tendrá un cierto nivel de razón, pero no será suficiente para convertirse en ciudadano.

En tercer lugar, el trabajo en esclavitud será otra de las consecuencias del sometimiento. El conquistado tendrá que responder al conquistador con trabajo, que también es parte del proceso de ciudadanía. Sin embargo, este trabajo que el conquistado realizará no tendrá un salario justo, sino será una forma de ayudar al conquistador a aprovechar la propiedad que ahora le pertenece. Esto es una forma de interpretación de lo que McPherson comentando a Locke llama la racionalidad diferenciada:

"La idea de Locke de una racionalidad diferenciada justificaba como natural no ya la esclavitud pero sí la subordinación de una parte del pueblo por su continua enajenación contractual de su capacidad para trabajar".12

El término "racionalidad diferenciada" se refiere a que, si bien todos tienen racionalidad, no todos tienen el mismo nivel de razón. La clase trabajadora por ejemplo, debido a que no tiene racionalidad, no puede ser miembro en pleno del cuerpo político. Su deber sólo será aportar lo necesario para la sociedad con su trabajo.

En cuarto lugar, el conquistado muestra irracionalidad al resistirse a la labor de los conquistadores. La resistencia a la dominación también es considerada un acto de irracionalidad; si esta resistencia se da, el conquistador puede tratar al irracional como cosa, como inferior, como ente, según Dussel.

En este proceso de colonización, el ego conquiro no sólo se apropia del territorio, sino también de la persona. Se apropia porque tiene la capacidad racional para "hacer suyo" el territorio y las personas que lo habitan. Los conquistados entonces, tendrán que someterse a las “disposiciones de apropiación” del conquistador, ya que estos últimos tienen el dynamis para administrar los territorios conquistados y sacarles provecho. El trabajo explotador será la expresión máxima de la praxis de dominación. Sólo de esa manera el conquistado se considerará útil para el 
conquistador. Sin embargo, hay una especie de transición en el trabajo: mientras el conquistado usaba el fruto de su trabajo para su propio provecho, ahora usará el fruto de su trabajo para provecho del conquistador. McPherson afirma que Locke hacía referencia a la propiedad, no sólo como un concepto económico, sino personal.

La irracionalidad del conquistado le brinda al conquistador la oportunidad de poder manipular ideológicamente al conquistador.

Este sometimiento tendrá también consecuencias políticas, generando la dialéctica centro-periferia. ${ }^{13}$ Europa, especialmente España, a razón del descubrimiento, deja de ser ignorada por el mundo de entonces y pasa a ser el "centro" del mundo; por tanto, las tierras y personas conquistadas constituirán la "periferia". En esto consiste para Dussel, el proceso de configuración de la subjetividad moderna. No es un proceso anecdótico e histórico, sino ideológico y ontológico, que consiste en una forma de concebir el "mundo de la vida" que lleva a imponer una forma de ser, pensar y actuar. Esa forma de pensar y esta praxis es, precisamente, que Europa se constituye y legitima como el "centro" del mundo, el "imperio" que somete ${ }^{14}$. España se muestra ante Europa como el "centro" de todo y el victimario conquistador (español) se constituye en sujeto. El ego conquiro por tanto se desenvolverá en ese mundo como un Señor y Amo.

El victimario se constituye en sujeto de dominio cuando pasa de ser alguien insignificante a ser un referente mundial, universal. En el "ego" del "descubridorconquistador" se pasa de la Edad Media renacentista a la Edad Moderna. Europa pasa de ser una "particularidad sitiada"15 a ser una "universalidad descubridora". España deja de ser sometida por los árabes dejando atrás su situación de particularidad e insignificancia y comienza a sentirse capacitada para inventar su propia imagen y semejanza. El victimario es entonces un sujeto que pasa de ser olvidado por el mundo, a ser el centro del mundo. Sin embargo, él "no tiene conciencia" de ser victimario porque cree que su praxis sólo es una manera de proceder, de acuerdo a la "ley natural", que afirmará posteriormente Locke ${ }^{16}$. También aquí podemos hacer otra precisión: el victimario que llega a América, era víctima en Europa; la mayoría procedía de sectores marginales de la España de entonces. También en el conquistador se vive una transformación: pasa de ser víctima del sistema europeo de entonces a ser victimario y miembro de la élite económica de esa época.

El ego moderno se ha confrontado al no-ego, es decir, al sujeto del Nuevo Mundo. Europa, o España: como representación del ego conquiro, verá entonces a los otros como objetos. Europa sería una especie de sujeto que reduce al mundo de la vida y al hombre que lo habita a una cosa, a un objeto, en el sentido de lo que

13. Cfr. Dussel, E., Filosofía de la liberación. Nueva América, Bogotá, 1996. pp. 14-15ss.

14. Con relación a la idea de Europa como el centro, cfr. Dussel E., El encubrimiento del otro, op. cit., p. 30ss.

15. Ibid., p 34.

16. John Locke hace referencia al tema de la ley natural en LOCKE, J. La ley de la naturaleza. Tecnos, Madrid, 2007, pp. 3-6. 
se pone delante de sus ojos. ${ }^{17}$ En definitiva, lo que se pone delante de sus ojos no es una persona, un "otro", sino un ser inanimado, algo que puede usar para sus propósitos económicos, políticos, sociales y personales.

La constitución del ego conquiro es ontológico-existencial, es decir, la imposición de un ser sobre otro ser ya constituido en su propio "mundo de la vida"18. La perspectiva ontológica se refiere a la dialéctica de dominación: el sujeto dominador reduce a objeto al no-sujeto dominado; lo considera un no-ser.

Para Dussel, "la modernidad no comienza con Descartes, sino con la conquista de América"19. Cristóbal Colón es el primer moderno, el primer ejemplo de ego conquiro ${ }^{20}$. Dussel afirma que el ego conquiro es la "protohistoria de la constitución del ego cogito"21. La historia del ego conquiro, según Dussel, es clave para entender el ego cogito.

Tomando en cuenta lo anterior, el conquistador, dominador, contribuirá al paso la "animalización", a la "humanización" del conquistado, dominado. Con proceso de animalización entendemos la primera manera en que el ego conquiro ve al indígena (como animal); como "humanización”, entendemos aquí el proceso en que ese "animal" pasa a "ser humano" desde la perspectiva del victimario y desde el pensamiento occidental. El indígena-conquistado se convierte a la manera occidental de ser, a imagen y semejanza de Europa. Los valores, tradiciones y religión propios de la cultura europea pasarán a formar parte de su mundo de la vida. Para ello, el ego conquiro usará un discurso para implantar esa idea en el indígena. El discurso consistirá en introducir en el indígena la idea de "ser dominado y dejarse someter", como una forma de ser ciudadano. Este proceso se verá como "natural”.

En este momento aparece el pensamiento de John Locke con el tema de la relación entre individuo y propiedad. Para Locke todo hombre tiene derecho por naturaleza a poseer algo. Esta posesión sólo es posible a partir del derecho a la vida y al trabajo: "Así a partir de los dos postulados, que los hombres tienen derecho a conservar su vida y que el trabajo de un hombre es propiedad suya, justifica Locke la apropiación individual del fruto de la tierra originalmente entregado a la humanidad en común". ${ }^{22}$ Es decir, la labor del ego conquiro es justificable porque la apropiación de la tierra es algo que Dios ha otorgado

17. Dussel, El encubrimiento del otro, op. cit., p. 36

18. Cfr. ibid, p. 23

19. Citado por Dussel en ibid., pp. 23-24.

20. Esta idea de Dussel es diferente a la que propone Zvetan Todorov, quien afirma que el fin primario de Colón no es el oro y la riqueza, sino el reconocimiento, por parte de los reyes de España, de ser descubridor más que un buscador de riquezas; su ideal consistió en llevar la fe cristiana a los pueblos conquistados. El afán de riqueza sólo estaba en la mente de los marinos que lo acompañaban. Cfr. TODOROV, Zvetan. La conquista de América. El problema del Otro. Siglo XXI, México, 1998, pp. 12-18.

21. Dussel, El encubrimiento del otro, op. cit., p. 47

22. Cfr. MCPHERSON, C., La teoría política del individualismo posesivo, op. cit., p. 199. 
al hombre; los conquistados desconocen este principio y el conquistador se encargará de dárselos a conocer con el discurso y con la praxis.

En "Europa, Modernidad y Eurocentrismo"23, Dussel habla de las formas en que se va construyendo esa mitología de la modernidad:

a- La civilización moderna se va a comprender a sí misma como superior y por lo tanto, se considera el centro del mundo;

b- esa superioridad obliga a "civilizar" a aquellos que se encuentran en condición inferior;

c- el método a seguir tiene que ser exclusivamente europeo, a través de la "falacia desarrollista", es decir, creer que "civilizar al indígena", es decir, que adopte la ideología y la manera de pensar europea, ayudará a su progreso; el desarrollo es el método de la colonización. ${ }^{24}$

\section{Colonización y eurocentrismo}

La colonización, como hemos dicho, consiste en la acción de insertar a los sometidos en la modernidad, occidentalizarlos. Aimée Cesaire, hablando de la colonización expresa lo siguiente:

\footnotetext{
"Eso significa que lo esencial aquí es ver claro y pensar claro, entender atrevidamente, responder claro a la inocente pregunta inicial: ¿qué es, en su principio la colonización? Reconocer que ésta no es evangelización, ni empresa filantrópica, ni voluntad de hacer retroceder las fronteras de la ignorancia, de la enfermedad, de la tiranía; ni expansión de Dios, ni extensión del Derecho; admitir de una vez por todas, sin voluntad de chistar por las consecuencias, que en la colonización el gesto decisivo es el del aventurero y el del pirata, el del tendero a lo grande y el del armador...el del apetito y el de la fuerza, con la maléfica sombra proyectada desde atrás por una forma de civilización que en un momento de su historia se siente obligada, endógenamente, a extender la competencia de sus economías antagónicas a escala mundial.”25
}

El texto citado muestra cómo la praxis de la colonización se encubre con valores como evangelización, empresa filantrópica (de ayuda desinteresada y humanitaria hacia el otro), encuentro amistoso. Estos valores sirven para legitimar la capacidad del conquistador de sentirse el amo y señor de las tierras conquistadas. Al mismo tiempo, la colonización es también una empresa económica y una forma de demostrar el poder del conquistador frente a otras naciones que se dedican a la conquista. En definitiva, es la forma de demostrar el kratos (como dominio), no el dynamis (como posibilidad).

25. CESAIRE, Aimé, Discurso sobre el colonialismo. Akal, Madrid, 2006, p. 14. 
La "colonización", en consecuencia, significa una movimiento cultural e ideológico en los siguientes aspectos: sustituye la forma propia de organización política del conquistado por una cultura y organización política basada en la visión de "ciudadanía"; sustituye los ritos y costumbres religiosas de las culturas conquistadas, por la "religión universal-católica" del ego conquiro; y finalmente, sustituye las relaciones interpersonales, propias de la cultura conquistada, por un modo de relación conquistador-conquistado; opresor-oprimido.

Desde una dimensión geopolítica, Europa expande su dominio. En la historia había sólo tres grandes lugares conocidos: Europa, Asia y África. Ahora también América formará parte de su periferia. El término que mejor describe este afán de dominio, de acuerdo a Dussel y a otros filósofos latinoamericanos ${ }^{26}$, es el Eurocentrismo y su base la falacia desarrollista ${ }^{27}$, es decir, una posición ontológica por la que se piensa que el desarrollo (desarrollismo) que siguió Europa, deberá ser seguido unilinealmente por cualquier otra cultura. Europa se convierte en el centro de referencia del mundo de entonces. Sin embargo, el punto de partida de dicho término es, para Dussel, el acontecimiento de la conquista y la colonización de América.

El eurocentrismo es la expresión ideológica del ego conquiro, es su bandera de batalla y se expresa en las teorías de la Ilustración en Kant y en las "Lecciones sobre filosofía de la historia" de Hegel. Kant va a expresar su eurocentrismo a través de la frase "la llustración es la salida de la humanidad de su inmadurez culpable”. Frente a esta expresión, Dussel va a plantear la siguiente pregunta:

"Un africano en Africa o como esclavo en Estados Unidos en el s. XVIII, un indígena en México o un mestizo latinoamericano posteriormente, ¿deben ser considerados en ese estado de culpable inmadurez?"28

Los sujetos sometidos, (africanos o mestizos) por tanto, son responsables de su inmadurez porque no hacen uso de su razón y por lo tanto, necesitan que se les introduzca en ella. ¿Qué se entiende entonces por razón? De acuerdo a la visión del conquistador, razón puede ser entendida como la capacidad de alcanzar una forma de pensar y de ser (ontología) al estilo europeo-occidental.

Dussel ilustra el problema del eurocentrismo en la filosofía de Hegel. En el filósofo alemán se plantea una relación entre el antiguo mundo y el nuevo mundo. Y este último es puesto en condiciones de inferioridad. Dussel trabajará este argumento siguiendo algunas de las tesis de Hegel como las que se muestran a continuación:

26. Santiago Castro Gómez hace referencia a otros filósofos que se enfocan en hablar del Eurocentrismo como Walter Mignolo, Rodolfo Kusch y Enrique Dussel. Cf. CASTRO, S., Crítica de la razón latinoamericana. Puvill, Barcelona, 1996, pp. 165-170.

27. Dussel aborda la falacia desarrollista en 1492: el encubrimiento del otro, op. cit., pp. 13-22.

28. Ibid p. 14. 
En primer lugar, la historia mundial está caracterizada por la autorrealización de Dios, de la razón y de la libertad. De acuerdo a esta afirmación, lo que se pretende es llegar a la universalización de la religión, de la filosofía y de la ética. En segundo lugar, el desarrollo es el movimiento mismo del "Concepto" hasta culminar en la "Idea". El desarrollo es un proceso que comienza con un concepto que puede desembocar en una teoría que puede ser universalizable y totalizadora. En tercer lugar, al afirmar Hegel que la Historia llega a su fin en Europa y Asia es su inicio, deja de lado a América y a África. Incluso, aunque Asia sea su inicio, esto no significa que esta región salga de su inmadurez. Tanto América como África no participan de la historia mundial porque, según Hegel, están en condiciones de inferioridad con respecto a Europa. Esta inferioridad desemboca en una anulación tanto de los países como de los habitantes de esas regiones. Asia queda únicamente en un estado de infancia, de inmadurez y, por tanto, es excluida de la historia. No obstante, al final sólo queda Europa como centro y fin de la historia y va a reflejar también una actitud de soberbia de Europa hacia las regiones de Asia, África y América Latina.

Hegel afirmará que en definitiva el Nuevo Mundo es la cultura germana (y también europea), que asimismo, es expresión de la Totalidad. La Totalidad es para Hegel, desembocar en la filosofía del Espíritu. Es decir que los pueblos germanos ( $\mathrm{y}$ europeos) tienen todo el derecho a imponer su Totalidad a los países de condición inferior. Son estos pueblos, los germanos, quienes tienen derecho al desarrollo; ningún otro pueblo tiene este derecho. En consecuencia, llegamos a una sacralización y divinización del poder imperial europeo por estos planteamientos de Hegel.

El proceso de descubrimiento y sobre todo el de conquista, serán claves en la constitución del ego moderno y quedará constituido como una subjetividad que será "centro" y "fin de la historia"29. La "periferia" queda entonces como el lugar o espacio que tiene Europa para ejercer y consolidar su dominación. Al final de este proceso lo que se descubre es, por un lado, la consolidación del dominio europeo; por otro lado, su capacidad para destruir y minusvalorar las culturas de la periferia de forma violenta. Es una forma de mostrar no sólo su núcleo racional, sino también su dimensión de irracionalidad violenta y desmesurada.

Al final, la totalidad va a desembocar, de acuerdo a Dussel, en la dialéctica racionalidad e irracionalidad que favorece a la Modernidad. Sin embargo, en el afán de querer dominar y someter a otros pueblos, demuestra más bien una actitud de irracionalidad, expresada en una praxis caracterizada por la violencia. Conclusión

Estas críticas de Dussel a las visiones de la modernidad han sido valiosas no sólo para la filosofía, sino para la historia, las ciencias sociales, la política y la 
economía. Entre los aspectos rescatables que encontramos en esta propuesta de ego (conquiro) están los siguientes:

En primer lugar, desenmascarar la historia del ego conquiro: el descubrimiento en la realidad se volvió un encubrimiento del Otro. Es decir, el interés de Dussel se centra en ver la otra cara del descubrimiento, el encubrimiento, que quiere decir encubrir la conquista violenta que tiene del indígena con la expresión "encuentro amistoso", "encuentro de dos mundos". La importancia que tiene esto para la historia es que no sólo se debe valorar la historia del "vencedor", sino también la del "vencido". En nuestras escuelas, en los medios de comunicación, en el periódico, en la radio, la historia de la conquista y colonización es desde el ego conquiro y no desde el conquistado.

En segundo lugar, para las ciencias sociales, lo valioso está en reivindicar el valor del dominado como protagonista de su historia, en medio de una situación en la que ha sido anulado. Dussel espera que la historia, en este sentido, se ponga a favor de los dominados no sólo para rescatarlos, sino para que incluso los grupos dominados actuales (indígenas, campesinos, obreros) se sientan protagonistas de su propia historia. Pero para sentirse protagonistas de su historia, es necesario que tomen conciencia de la injusticia de que han sido víctimas. Reyes Mate afirma que la memoria es el elemento necesario para recordar tanto la injusticia, como la justicia ${ }^{30}$. Para exigir justicia, es necesario que las víctimas sean conscientes de la situación de injusticia que viven. Recordar esas situaciones y sus consecuencias, es el camino más adecuado para que se haga justicia a favor de ellos.

Para la economía, desenmascarar la relación de trabajo entre el conquistador y el conquistado. Dicha relación se demuestra en que el sometido tiene que producir con una remuneración injusta; la propiedad del conquistado es ahora propiedad del conquistador. Aquí no sólo hablamos de bienes, sino de personas.

Entre los aspectos discutibles se destaca que aun cuando es novedoso afirmar que la modernidad comienza desde la conquista de América, es problemático para la filosofía. Si bien es cierto que éste es un planteamiento original de Dussel, ha sido bastante criticado desde diferentes perspectivas.

La primera crítica, que viene de un periodista, se centra por ejemplo que España, cuando hizo su labor de exploración y descubrimiento, no había entrado en la dinámica de la Modernidad que ya tenían otros países europeos. Por tanto, resultaría anacrónico afirmar que España en ese momento es el gestor de la Modernidad y más anacrónico aún es describir a Colón como el "prime moderno"31.

30. REYES Mate, Manuel. Tratado de la injusticia. Anthropos, Barcelona, 2011, p. 292.

31. Tal es el caso de José Cornejo, que afirma que Dussel desemboca en una crítica maniquea de la conquista española. Quizá lo más valioso de esta crítica está en sostener que todavía no se puede hablar de España como gestora de la Modernidad y como un país, ya que todavía su organización era monárquica. Cf. Cornejo, J., "Breve ensayo crítico sobre la modernidad en Dussel”, www.la 
Karl Otto Apel, por su parte, en un debate que sostuvo con Enrique Dussel, está de acuerdo con la situación de sometimiento de forma violenta que vivió el indígena. Él lo afirma de la siguiente forma:

\begin{abstract}
“Aproximadamente en el año 1500, las poblaciones indígenas de América, del África negra y de grandes partes de Asia, fueron arrancadas (en general de forma violenta) de sus condiciones naturales y socioculturales de vida, siendo también fuertemente diezmadas o exterminadas de plano; fueron asimismo despojadas en parte de sus culturas avanzadas, así como de su orden social; fueron esclavizadas y, en cualquier caso, condenadas a convertirse en un "grupo marginal" extremadamente pobre de la humanidad, un grupo, además, dependiente económica y culturalmente del Norte"32.
\end{abstract}

Lo que Apel ve como injusto es el hecho del sometimiento en forma violenta hacia los aborígenes de América, que les hayan quitado sus culturas, sus tradiciones, y los hayan dejado en una condición de pobreza y marginación. Apel llega a decir que a consecuencia de la conquista, estos aborígenes pasan a ser un "grupo marginal", es decir, no forman parte de la estructura de la ciudadanía, no tienen participación política y son un grupo que es dependiente cultural y económicamente del Norte.

Santiago Castro Gómez por otro lado, elabora una crítica al planteamiento del eurocentrismo en Dussel, en base a dos aspectos.

En primer lugar, él afirma lo siguiente:

“La filosofía de la liberación propuesta por Dussel se describe a sí misma utilizando los mismos signos de identidad definidos por aquella modernidad que pretende superar."

Es decir, que la filosofía de la liberación de Dussel se identifica no con parámetros propios de la filosofía de la liberación, sino de la Modernidad europea. Interpretando a Castro Gómez, él quiere decir que plantear la filosofía de la liberación desde argumentos de la filosofía de la Modernidad, no es la manera de superar a la Modernidad. Él propone el "giro decolonial" como la alternativa de la filosofía latinoamericana frente a la Modernidad. Es decir, no recurrir a los argumentos de la filosofía europea, sino a los argumentos mismos de los grupos que han sido colonizados y sometidos. En esto consiste para Castro Gómez el "giro decolonial".

En segundo lugar, creer que la liberación de los sujetos oprimidos depende de un "centro" que es universal, no toma en cuenta la diversidad de esos sujetos 
oprimidos. El desafío es incluir a todos los "actores empíricos" (indígenas, campesinos, afros, gays, lesbianas, etc.) en la liberación de su opresión para que todos, desde su particularidad, se sientan involucrados en su proceso de liberación.

\section{BIBLIOGRAFÍA y REFERENCIAS ELECTRÓNICAS}

1. DUSSEL, E., Método para una filosofía de la liberación. Sígueme, Salamanca, 1974.

2. DUSSEL, E., Filosofía de la liberación. Nueva América, Bogotá, 1996

3. DUSSEL, E. 1492. El encubrimiento del otro. Hacia el origen del mito de la modernidad. Plural Edit., La Paz, 1994.

4. DUSSEL, E., Ética de la liberación en la edad de la globalización y la exclusión. Trotta, Madrid, 1998.

5. HONET, Axel, La sociedad del reconocimiento. Crítica, Barcelona, 1997.

6. DE LAS CASAS, Bartolome, La destrucción de las indias. Clásicos Ucieza, Barcelona, 1997.

7. MCPHERSON, C. La teoría política del individualismo posesivo. De Hobbes a Locke. Trotta, Madrid, 2005.

8. LOCKE, J. La ley de la naturaleza. Tecnos, Madrid, 2007.

9. TODOROV, Zvetan. La conquista de América. El problema del Otro. Siglo XXI, México, 1998.

10. CESAIRE, Aime, Discurso sobre el colonialismo. Akal, Madrid, 2006.

11. CASTRO, S., Crítica de la razón latinoamericana. Puvill, Barcelona, 1996.

12. REYES Mate, Manuel. Tratado de la injusticia. Anthropos, Barcelona, 2011.

13. APPEL, K. y DUSSEL E. Ética del discurso y ética de la liberación. Trotta, Madrid, 2004.

14. RUIZ, J., De Heidegger a Habermas. Hermenéutica y fundamentación última en la filosofía contemporánea. Herder, Barcelona, 1997

15. www.enriquedussel.org

16. http://www.lainsignia.org/2007/diciembre/soc_003.ht 